\title{
Short- and long-term outcomes of very low birth weight infants in Korea: Korean Neonatal Network update in 2019
}

\author{
Jang Hoon Lee, MD, $\mathrm{PhD}^{1}, *$, Young Ah Youn, MD, $\mathrm{PhD}^{2, *}$, Yun Sil Chang, MD, $\mathrm{PhD}^{3}$; and the Korean Neonatal Network \\ ${ }^{1}$ Department of Pediatrics, Ajou University School of Medicine, Suwon, Korea; ${ }^{2}$ Department of Pediatrics, Seoul St. Mary's Hospital, College of Medicine, The Catholic \\ University of Korea, Seoul, Korea; ${ }^{3}$ Department of Pediatrics, Samsung Medical Center, Sungkyunkwan University School of Medicine, Seoul, Korea
}

Korea currently has the world's lowest birth rate but a rapidly inreasing number of preterm infants. The Korean Neonatal Network (KNN), launched by the Korean Society of Neonatology under the support of Korea Centers for Disease Control, has collected population-based data for very low birth weight infants (VLBWIs) born in Korea since 2013. In terms of the short-term outcomes of VLBWIs born from 2013 to 2016 registered in the KNN, the survival rate of all VLBWIs was 86\%. Respiratory distress syndrome and bronchopulmonary dysplasia were observed in $78 \%$ and $30 \%$ of all VLBWIs, respectively. Necrotizing enterocolitis occurred in $7 \%$, while $8 \%$ of the VLBWIs needed therapy for retinopathy of prematurity in the neonatal intensive care unit (NICU). Sepsis occurred in 21\% during their NICU stay. Intraventricular hemorrhage (grade $\geq \mathrm{III}$ ) was diagnosed in $10 \%$. In terms of the long-term outcomes for VLBWIs born from 2013 to 2014 registered in the KNN, the post-discharge mortality rate was approximately $1.2 \%-1.5 \%$, mainly owing to their underlying illness. Nearly half of the VLBWIs were readmitted to the hospital at least once in their first 1-2 years of life, mostly as a result of respiratory diseases. The overall prevalence of cerebral palsy was $6.2 \%-6.6 \%$ in Korea. Bilateral blindness was reported in $0.2 \%-0.3 \%$ of VLBWIs, while bilateral hearing loss was found in $0.8 \%-1.9 \%$. Since its establishment, the KNN has published annual reports and papers that facilitate the improvement of VLBWI outcome and the formulation of essential healthcare policies in Korea.

Key words: Very low birth weight infants, Premature infants, Neonatal intensive care unit

\section{Key message}

The Korean Neonatal Network (KNN) has collected population-based data for very low birth weight infants (VLBWIs) born in Korea since 2013. The survival rate of all VLBWIs was $86 \%$ in Korea. The overall prevalence of cerebral palsy was 6.2\%$6.6 \%$. Bilateral blindness and hearing loss were reported in $0.2 \%-0.3 \%, 0.8 \%-1.9 \%$, respectively. The $\mathrm{KNN}$ has published annual reports and papers for facilitating the improvement of VLBWIs outcome in Korea.

\section{Introduction}

In recent years, Korea has encountered 2 major health issues related to perinatal and neonatal care. The first issue is an extremely low overall birth rate (0.977 in 2018), the lowest recorded rate worldwide. The annual number of newborns in Korea was approximately 326,900 in 2018, which is approximately a 50\% reduction from 720,000 at 20 years ago, which creates difficulty preparing for the national driving force of the future. ${ }^{1)}$ The second issue is the rapid increase in the number of high-risk infants born prematurely before 37 weeks of pregnancy as a result of the increasing age at marriage and pregnancy and the more frequent use of infertility procedures. ${ }^{2)}$ With the number of newborns decreasing every year coupled with the increasing number of high-risk newborns, it has become crucial for the country's health sector to pay attention to the current situation.

Among premature infants, approximately 2,500 very low birth weight infants (VLBWIs; birth weight $<1.5 \mathrm{~kg}$ ) requiring neonatal intensive care are born every year. This is more than a 2-fold increase from approximately 1,000 from 20 years ago. ${ }^{3)}$ Given the marked decrease in the total number of newborns, the overall number and ratio of VLBWIs have greatly increased. Because these newborns are considerably small and fragile, their probability of mortality and morbidity is high, so their survival and prevalence rates are used to assess neonatal intensive care quality. ${ }^{4)}$ However, these infants comprise approximately $1 \%$ of all births. To investigate and establish various proper measures for these small infants, the collection of a large amount of data by nationwide and international neonatal networks is preferred over research efforts by a single institution. Developed countries have been maintaining an active nationwide neonatal network under various governmental supports for decades through which practical research with a sufficient understanding of the national status of these high-risk newborns is being conducted to improve treatment quality.

Corresponding author: Yun Sil Chang, MD, PhD. Department of Pediatrics, Samsung Medical Center, Sungkyunkwan University School of Medicine, 81 Irwon-ro, Gangnam-gu, Seoul 06351, Korea

凶E-mail: yschang@skku.edu, https://orcid.org/0000-0001-9201-2938

*These authors contributed equally to this study as co-first authors.

Received: 15 July, 2019, Revised: 9 December, 2019, Accepted: 11 December, 2019

This is an open-access article distributed under the terms of the Creative Commons Attribution Non-Commercial License (http://creativecommons.org/licenses/bync/4.0/) which permits unrestricted non-commercial use, distribution, and reproduction in any medium, provided the original work is properly cited.

Copyright (c) 2020 by The Korean Pediatric Society 


\section{Korean Neonatal Network update}

The Korean Neonatal Network (KNN) was launched on April 15, 2013 by the Korean Society of Neonatology under the support of the Korea Centers for Disease Control (KCDC). The $\mathrm{KNN}$ is composed of a web-based registry of VLBWIs through voluntary participation of hospitals nationwide. Registration servers and data storage are securely maintained at the KCDC. This provides the basis for facilitating multicenter clinical studies to collect national epidemiological data on VLBWIs and improve their prognosis. ${ }^{5)}$

At present, 70 hospitals among nearly 100 neonatal intensive care units (NICUs) nationwide (Fig. 1) are participating in the $\mathrm{KNN}$, collecting data from 2,000 to 2,400 infants annually, accounting for 70\%-80\% of VLBWIs born each year. According to Statistics Korea, 357,771 infants were born in South Korea in 2017, of whom 2,530 (0.71\%) were VLBWIs weighing less than $1.5 \mathrm{~kg}$. ${ }^{6}$ The 2,140 VLBWIs born in 2017 who were registered with the KNN had a considerably high demographic representation of $85 \%$ of all VLBWIs in Korea. ${ }^{6}$ In addition, the KNN collects data on long-term prognosis and allows the follow-up of VLBWIs for up to 3 years after registration, making it an important basis for the establishment of short- and long-term healthcare policies. To date, the cumulative number of VLBWIs registered in the KNN exceeds $12,500,{ }^{7)}$ and their long-term follow-up rate is about $70 \%$ at $18-24$ months (2 years) and approximately 50\% at 33-39 months after birth. $\left.{ }^{6}\right)$ Through the accumulation of such a large amount of data, the $\mathrm{KNN}$ is expected to make a significant contribution to improving Korean neonatal intensive care quality.

The KNN provides an annual overview adjusting for the prevalence and mortality rates in each institution compared to all the other participating hospitals, which helps compare and study the level and direction of treatment for VLBWIs for each institution; consequently, this provides an important basis upon which to improve treatment quality. As such, the $\mathrm{KNN}$ provides the basis for quality improvement (QI) by providing feedback for each institution based on strict refinement of data and statistical analysis, selecting the benchmarking index and applying program development. The goal of expanding the application of the QI program of the $\mathrm{KNN}$ is to improve neonatal intensive care quality nationwide. .) $^{2}$

The KNN has also been conducting various clinical studies with numerous subjects based on the accumulated information on VLBWIs in Korea related to both morbidity and mortality. The KNN has published approximately 20 international peer-

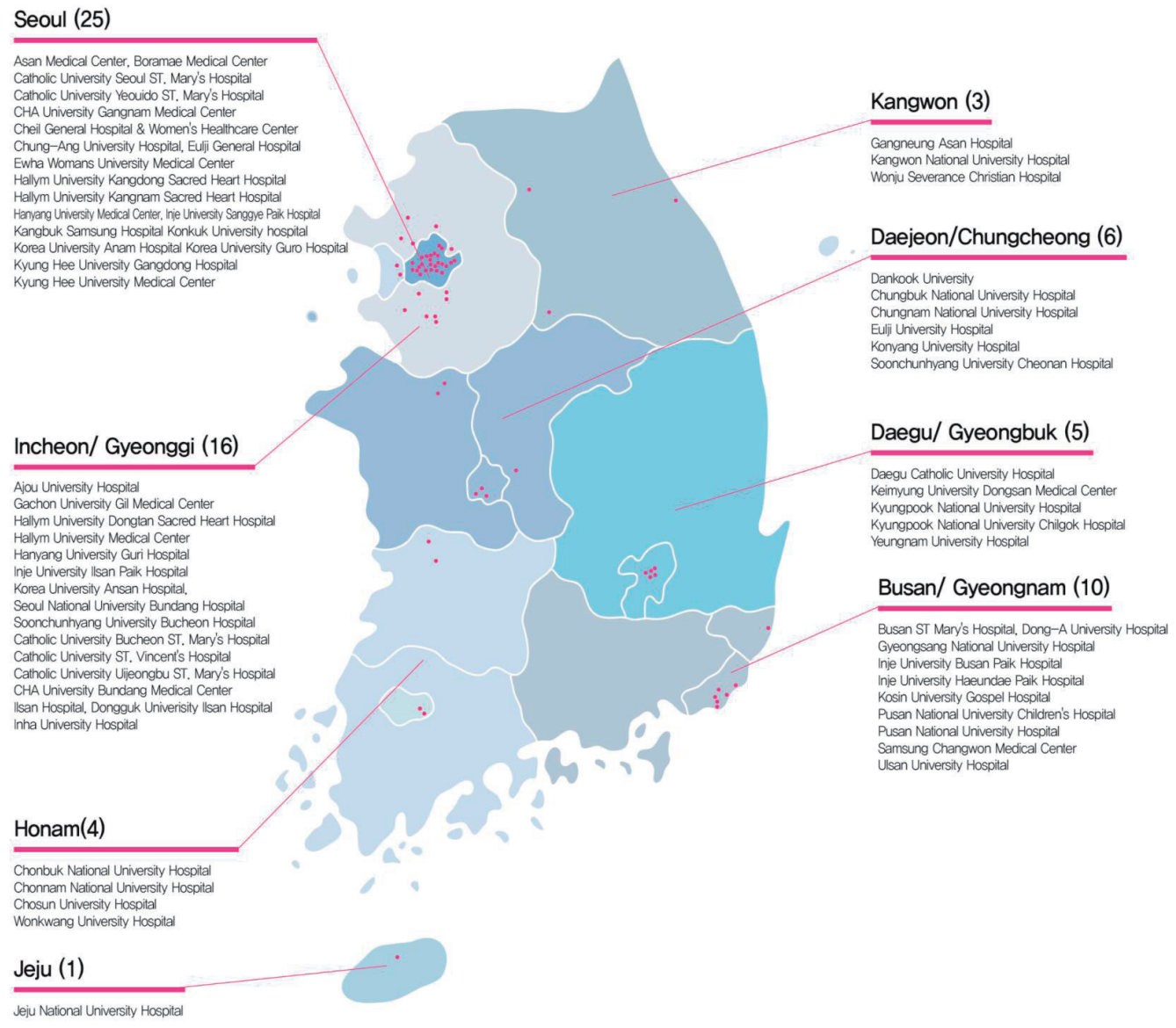

Fig. 1. National distribution of 70 neonatal intensive care units participating in the Korean Neonatal Network. Available from: http://www.knn.or.kr/index.jsp. 
reviewed journal papers to date and is still actively publishing highquality papers, which plays an important role in the academic development of neonatology in Korea.

Moreover, the $\mathrm{KNN}$ is educating the public and raising awareness on treatment results, perception, long-term follow-up, and healthcare for VLBWIs by publishing an annual report for the general public as part of the annual reports published. By informing the public that VLBWIs require continued healthcare through follow-up at medical institutions for a certain period after NICU discharge, the reports play a significant facilitating role in helping them adapt and be cared for as healthy Korean citizens. These KNN activities can contribute to the establishment of proper healthcare policies for high-risk newborns while providing necessary data through government interactions in the future.

Furthermore, the KNN plans to join the International Network for Evaluation of Outcomes of Neonates (iNeo), an international network collecting data on VLBWIs in 11 countries and 10 newborn networks. By joining the iNeo, the $\mathrm{KNN}$ is expected to actively promote QI on a national level based on objectified international data and a comparative analysis of factors such as morbidity and mortality rates among countries.

As such, the KNN plays an important role in Korean neonatology and neonatal health; it can help formulate future plans that are crucial in addressing the extremely low fertility rate, thereby achieving continuous national support.

\section{Short-term outcomes of VLBWIs in KNN}

Preterm birth and the resulting complications are the leading causes of mortality in children younger than 5 years. ${ }^{8)}$ Preterm infants require long-term healthcare beyond the neonatal period. ${ }^{9}$ ) Therefore, managing and improving the neonatal outcomes of preterm infants in Korea, with the lowest birth rate worldwide, is important.

The KNN recently reported the findings of a populationbased study conducted in Korea to evaluate the survival rates and significant morbidities of VLBWIs. ${ }^{10)}$ This study included 8,269 VLBWIs born at a gestational age (GA) of $\geq 22$ weeks or transferred within 28 days after birth to the participating NICUs of the KNN between January 2013 and December 2016. From 2013 to 2016, a total of 49, 55, 60, and 66 NICUs participated annually and registered 1,396, 2,123, 2,392, and 2,358 VLBWIs in the KNN registry, respectively. Of all VLBWIs in this study, 35\% were born as multiples, and $34 \%$ of their mothers were older than 35 years. Antenatal steroids were administered to $76 \%$ of their mothers, and $77 \%$ of the infants were born via cesarean section. Of the mothers, $8 \%$ and $21 \%$ had diabetes and hypertension, respectively, during pregnancy. The survival rate of all VLBWIs in this study was $86 \%$; the rates were much lower in the infants with GAs of 22-23, 24-25, and 26-27 weeks (more immature VLBWIs) than in those with a $G A \geq 28$ weeks (Table 1). ${ }^{10)}$ Of all VLBWIs, 78\% and 30\% were diagnosed with respiratory distress syndrome (RDS) and moderate to severe bronchopulmonary dysplasia (BPD), respectively. The RDS rates decreased abruptly in the VLBWIs with GAs of 30-32 and >32 weeks. The BPD rates were much higher in the VLBWIs with GAs of 22-23, 24 25 , and 26-27 weeks than in those with a $G A \geq 28$ weeks. Of the total VLBWIs, 7\% were diagnosed with necrotizing enterocolitis (NEC), while 8\% needed therapy for retinopathy of prematurity (ROP) in the NICU. The rates of NEC and ROP in the VLBWIs with a GA of 22-23 weeks were 20\% and 20\%, respectively, and decreased as the GA of the subgroups increased. Sepsis occurred in 21\% of all VLBWIs during the NICU stay; specifically, the rates of sepsis of the VLBWIs with GAs of 22-23, 24-25, and 26-27 weeks were much higher than those of the VLBWIs with a $\mathrm{GA} \geq 28$ weeks. Intraventricular hemorrhage (IVH; grade $\geq \mathrm{III}$ ) was diagnosed in 10\% of all VLBWIs; the IVH rates were much higher in the VLBWIs with GAs of 22-23 and 24-25 weeks than in those with a GA $\geq 26$ weeks. The neonatal outcomes of the VLBWIs enrolled in this study are shown in Table $2 .{ }^{10)}$ In this study, the survival rates of the VLBWIs with a GA of 22-23, 24-25, and 26-27 weeks were also much lower than those of the infants with a $G A \geq 28-29$ weeks. These prominent differences in the survival rates by GA were also seen in the international comparison with the findings of other developed countries. The overall survival rate of the VLBWIs at a GA of 24-29 weeks in the KNN was $84 \%$, comparable with most of the rates of other countries; however, the overall survival rates of the less mature infants at a GA of 24-26 weeks were much lower than those of

Table 1. Demographic data of very low birth weight infants of Korean Neonatal Network, 2013-2016

\begin{tabular}{|c|c|c|c|c|c|c|c|}
\hline Gestational age (wk) & $\begin{array}{c}22-23 \\
(n=372)\end{array}$ & $\begin{array}{c}24-25 \\
(n=1,156)\end{array}$ & $\begin{array}{c}26-27 \\
(n=1,644)\end{array}$ & $\begin{array}{c}28-29 \\
(n=2,191)\end{array}$ & $\begin{array}{c}30-32 \\
(n=2,078)\end{array}$ & $\begin{array}{c}>32 \\
(n=828)\end{array}$ & $\begin{array}{c}\text { Total } \\
(n=8,269)\end{array}$ \\
\hline Male & $52(47-58)$ & $52(49-55)$ & $53(50-55)$ & $51(49-53)$ & $47(45-50)$ & $47(44-50)$ & $50(49-51)$ \\
\hline Multiple birth & $39(34-44)$ & $34(31-36)$ & $29(27-31)$ & $34(32-36)$ & $41(39-43)$ & $38(35-42)$ & $35(34-36)$ \\
\hline Maternal age $<20 \mathrm{yr}$ & $0(0-2)$ & $1(0-1)$ & $0(0-1)$ & $0(0-1)$ & $0(0-1)$ & $0(0-1)$ & $0(0-1)$ \\
\hline Maternal age $>35 \mathrm{yr}$ & $30(26-35)$ & $32(30-35)$ & $36(34-38)$ & $32(31-35)$ & $34(32-36)$ & $35(32-39)$ & $34(33-35)$ \\
\hline Antenatal steroid & $63(58-68)$ & $79(76-81)$ & $82(80-84)$ & $81(79-83)$ & $80(79-82)$ & $45(42-49)$ & $76(75-77)$ \\
\hline Cesarean section & $49(43-54)$ & $71(68-74)$ & $74(71-76)$ & 77 (75-79) & $85(83-86)$ & $88(86-90)$ & $77(76-78)$ \\
\hline Maternal diabetes & $2(1-4)$ & $5(4-6)$ & $9(8-10)$ & $10(9-12)$ & $10(9-11)$ & $8(6-10)$ & $8(8-9)$ \\
\hline Maternal hypertension & $3(2-6)$ & $8(7-10)$ & $13(12-15)$ & $17(15-18)$ & $33(31-35)$ & $38(34-41)$ & $21(20-21)$ \\
\hline
\end{tabular}

Values are presented as percentage (range of probability: $95 \%$ confidence interval).

There is a significant difference among groups if the probability ranges do not overlap with each other.

Modified from Lee et al. J Korean Med Sci 2019;34:e40. ${ }^{10)}$ 
Table 2. Neonatal outcomes of very low birth weight infants of Korean Neonatal Network, 2013-2016

\begin{tabular}{|c|c|c|c|c|c|c|c|}
\hline Gestational age (wk) & $\begin{array}{c}22-23 \\
(n=372)\end{array}$ & $\begin{array}{c}24-25 \\
(n=1,156)\end{array}$ & $\begin{array}{c}26-27 \\
(n=1,644)\end{array}$ & $\begin{array}{c}28-29 \\
(n=2,191)\end{array}$ & $\begin{array}{c}30-32 \\
(n=2,078)\end{array}$ & $\begin{array}{c}>32 \\
(n=828)\end{array}$ & $\begin{array}{c}\text { Total } \\
(n=8,269)\end{array}$ \\
\hline Survival rate & $33(28-38)$ & $65(62-67)$ & $84(82-85)$ & $94(93-95)$ & $97(96-98)$ & 98 (97-99) & $86(8587)$ \\
\hline Respiratory distress syndrome & 98 (95-99) & $98(97-99)$ & $96(95-97)$ & $89(88-91)$ & $60(58-62)$ & $21(18-23)$ & 78 (77 79) \\
\hline BPD & $88(80-93)$ & $64(61-68)$ & $47(44-49)$ & $26(24-28)$ & $14(13-16)$ & $5(4-7)$ & $30(2931)$ \\
\hline ROP Tx. & $20(16-25)$ & $25(2328)$ & $11(9-12)$ & $3(2-4)$ & $1(0-1)$ & $0(0-1)$ & $8(78)$ \\
\hline $\mathrm{NEC} \geq \| \mathrm{la}$ & $20(16-25)$ & $15(13-17)$ & $9(8-11)$ & $4(3-5)$ & $3(2-3)$ & $2(1-4)$ & $7(67)$ \\
\hline Sepsis & $38(33-43)$ & $36(33-39)$ & $31(29-33)$ & $18(16-19)$ & $11(9-12)$ & $6(4-8)$ & $21(2022)$ \\
\hline Drug for PDA & $39(34-45)$ & $52(49-55)$ & $48(45-50)$ & $34(32-36)$ & $21(19-23)$ & $9(7-11)$ & $34(3335)$ \\
\hline Ligation of PDA & $18(14-23)$ & $25(23-28)$ & $18(16-20)$ & $7(6-9)$ & $3(3-4)$ & $2(1-3)$ & $11(1012)$ \\
\hline IVH (zgrade III) & $45(39-51)$ & $27(25-30)$ & $12(11-14)$ & $5(4-6)$ & $2(1-3)$ & $1(0-2)$ & $10(9$ 10) \\
\hline PVL & $15(11-20)$ & $12(10-15)$ & $11(9-12)$ & $8(7-9)$ & $5(4-6)$ & $2(1-3)$ & $8(79)$ \\
\hline
\end{tabular}

Values are presented as percentage (range of probability: $95 \%$ confidence interval).

There is a significant difference among groups if the probability ranges do not overlap with each other.

Modified from Lee et al. J Korean Med Sci 2019;34:e40.10)

infants in many other countries. ${ }^{10)} \mathrm{BPD}$, a representative chronic lung disease in newborn infants, results in higher mortality rates and more extended hospitalization stays. Infants with BPD are at increased risk of cardiovascular impairment, pulmonary sequelae, growth failure, and neurodevelopmental delay. ${ }^{11-13)}$ The BPD rate of VLBWIs with a GA of 23-31 weeks increased from $17.8 \%$ in 2007-2008 to 33\% in 2013-2014 in Korea. ${ }^{14)}$ Studies conducted in other countries also showed that an increase in the survival rate of infants with a lower GA and lower birth weight, risk factors for $\mathrm{BPD}$, leads to an inevitable increase in the rate of BPD. ${ }^{15-18)}$

Despite improvements in the neonatal outcomes of VLBWIs, the survival and morbidity rates of more immature infants with a GA of 22-27 weeks remain to be improved in Korea. Therefore, it is necessary to develop treatment strategies to improve the neonatal outcomes of VLBWIs in Korea.

\section{Long-term outcomes of VLBWls at the corrected 18-24 months age in KNN}

To evaluate the long-term outcomes, we reviewed registry data from the KNN collected for VLBWIs born between January 2013 and December 2014 in Korea. ${ }^{19,20)}$ Based on the KNN data, a total of 2,660 VLBWIs were assessed at the corrected 18-24 months of age. ${ }^{21)}$

The mean GA and birth weight were 291/7 $\pm 26 / 7$ weeks and $1,093 \pm 268 \mathrm{~g}$ in 2013 and 292/7 $\pm 26 / 7$ weeks and 1,125 \pm 261 $\mathrm{g}$ in 2014, respectively. The post-discharge mortality rate was approximately $1.2 \%-1.5 \%$, mainly owing to underlying illness. The infants at the $<50$ th percentile for height and head circumference accounted for more than half of the population of this study. Approximately half of the VLBWIs were readmitted to the hospital at least once in their first 1-2 years of life, mostly as a result of respiratory illnesses. Further, surgery for underlying health issues such as inguinal hernia required readmission in the first 1-2 years of life. The rate of the need for oxygen after discharge was 14\%-17\% (Table 3). ${ }^{10)}$ Of the 2,660 infants, 2,028 (76.2\%) were assessed for cerebral palsy (CP) at the corrected
18-24 months of age (Table 3). The overall prevalence of CP was $6.2 \%-6.6 \%$ in Korea from 2013 to 2014. Figs. 2 and $3^{19,20)}$ demonstrate the distribution of $\mathrm{CP}$ in an inverse relationship to GA. The prevalence of $\mathrm{CP}$ increased to $8.8 \%-9.6 \%$ in the infants born at a GA of 22-27 weeks; this rate steadily declined in the infants born at an estimated GA of 30 weeks (Pearson's productmoment correlation coefficient, -0.893 ; $95 \%$ confidence interval, -0.964 to $-0.701 ; P<0.001)$. However, in the infants born at a GA of 36 weeks who were born with severe intrauterine growth retardation and weighing less than $1,500 \mathrm{~g}$, the rate of $\mathrm{CP}$ increased up to $20 \%$ (Figs. 2 and 3). ${ }^{19-21)}$ Rehabilitative support after discharge was provided to approximately $35 \%-38 \%$ of the VLBWIs and speech therapy to $5.1 \%-5.7 \%$ at the corrected 18 24 months of age (Table 3). Regarding eye complications, bilateral blindness was reported in $0.2 \%-0.3 \%$ of the VLBWIs. The main ophthalmologic disorder in the VLBWIs was ROP, which affected approximately $30 \%-40 \%$. Bilateral hearing loss was observed in $0.8 \%-1.9 \%$, while a hearing aid was needed in approximately $0.3 \%-0.7 \%$ (Table 3 ).

The follow-up rate for the Bayley Scale Infant Development Second Edition (BSID-II) was low, probably because milder cases that were not referred to rehabilitation facilities may have been excluded. Only 631 infants (23.7\%) were assessed. Of them, 55 (22.4\%) in 2013 and 45 (24.1\%) in 2014 were at risk based on their mental developmental index (scores $<70$ ); further, 63 (25.6 $\%)$ in 2013 and 27 (14.4\%) in 2014 were at risk based on their psychomotor developmental index. For the BSID-III, the followup rate was even lower; therein, 198 infants (7.4\%) were enrolled. Of them, 6 (7.8\%) in 2013 and 5 (4.1\%) in 2014 were at risk of cognitive developmental impairment; 5 (6.5\%) in 2013 and 7 (5.8\%) in 2014 for language developmental impairment; and 10 (13\%) in 2013 and 4 (3.4\%) in 2014 for motor developmental impairment among the VLBWIs at the corrected 18 months of age (Table 4). ${ }^{21)}$

Currently, the KNN is following up these VLBWIs for longer periods, which may provide information on additional and clearer relationships with long-term outcomes. In the future, it will be necessary to observe minor neurodevelopmental sequelae such 
Table 3. Clinical characteristics and outcomes of very low birth weight infants $(n=2,660)$

\begin{tabular}{|c|c|c|}
\hline Variable & $2013(n=1,000)$ & $2014(n=1,660)$ \\
\hline Gestational age (wk) & $291 / 7 \pm 26 / 7$ & $292 / 7 \pm 26 / 7$ \\
\hline Birth weight (g) & $1,093 \pm 268$ & $1,125 \pm 261$ \\
\hline Male & $504(50.4)$ & $833(50.2)$ \\
\hline Post-discharge mortality & $15(1.5)$ & $20(1.2)$ \\
\hline Respiratory & $5(45.5)$ & $6(35.3)$ \\
\hline Underlying disease & $11(73.3)$ & $17(85.0)$ \\
\hline \multicolumn{3}{|l|}{ Growth at visit } \\
\hline Weight & $n=800$ & $n=1,091$ \\
\hline$<50$ th & $465(46.5)$ & $721(66.1)$ \\
\hline 50th-90th & $243(30.4)$ & 337 (30.9) \\
\hline Height & $n=753$ & $n=993$ \\
\hline$<50$ th & $482(64.0)$ & $622(62.6)$ \\
\hline 50th-90th & $219(29.1)$ & $325(32.7)$ \\
\hline Head circumference & $n=632$ & $n=811$ \\
\hline$<50$ th & $404(64.0)$ & $516(63.6)$ \\
\hline 50th-90th & $176(27.8)$ & 267 (32.9) \\
\hline Rehospitalizations ${ }^{\mathrm{a})}$ & $n=846$ & $n=1,182$ \\
\hline Respiratory & $262(44.9)$ & $349(47.5)$ \\
\hline Surgery & $135(23.2)$ & $168(22.8)$ \\
\hline Infection & $106(18.2)$ & $106(14.4)$ \\
\hline Medical treatment ${ }^{\mathrm{a})}$ & $n=846$ & $n=1,182$ \\
\hline Oxygen & $142(16.8)$ & $166(14.0)$ \\
\hline Ventilator & $53(6.3)$ & $60(5.1)$ \\
\hline Nasogastric tube feeding & $76(9.0)$ & $100(8.5)$ \\
\hline Cerebral palsy & $n=846$ & $n=1,182$ \\
\hline Diplegia & $28(3.3)$ & $46(3.9)$ \\
\hline Hemiplegia & $4(0.5)$ & $7(0.6)$ \\
\hline Quadriplegia & $24(2.8)$ & $20(1.7)$ \\
\hline Unknown & $21(2.5)$ & $47(4.0)$ \\
\hline \multicolumn{3}{|l|}{ Rehabilitative support } \\
\hline No & $512(60.5)$ & $748(63.2)$ \\
\hline Yes & $318(37.6)$ & $412(34.9)$ \\
\hline \multicolumn{3}{|l|}{ Language support } \\
\hline No & 779 (92.1) & $1081(91.5)$ \\
\hline Yes & $43(5.1)$ & $68(5.7)$ \\
\hline Eye and hearing & $n=846$ & $\mathrm{n}=1,182$ \\
\hline Blindness & $n=846$ & $n=1,134$ \\
\hline One-eye & $4(0.5)$ & $3(0.3)$ \\
\hline Both eyes & $2(0.2)$ & $3(0.3)$ \\
\hline Ophthalmologic disorders ${ }^{a)}$ & $120(14.2)$ & $179(15.1)$ \\
\hline Retinopathy of prematurity & $56(41.2)$ & $51(26.6)$ \\
\hline Glaucoma & 0 & $3(1.6)$ \\
\hline Cataract & $2(1.5)$ & $1(0.5)$ \\
\hline Strabismus & $29(21.3)$ & $40(20.8)$ \\
\hline Refraction abnormality & $15(11.0)$ & $11(5.7)$ \\
\hline Wearing glasses & $23(2.7)$ & $19(1.6)$ \\
\hline Hearing impairment ${ }^{a)}$ & $24(3.2)$ & $22(1.9)$ \\
\hline Unilateral & $10(1.3)$ & $12(1.0)$ \\
\hline Bilateral & $14(1.9)$ & $10(0.8)$ \\
\hline Hearing aid & $6(0.7)$ & $3(0.3)$ \\
\hline Need for cochlear impairment & $1(0.1)$ & $4(0.3)$ \\
\hline
\end{tabular}

as cognitive deficits, academic underachievement, ${ }^{22)}$ attentiondeficit hyperactivity disorder, and emotional troubles, ${ }^{23,24)}$ which may be undetectable during the neurodevelopmental assessment performed at the corrected 18-24 months of age.

\section{Conclusions}

Since its establishment in 2013, the KNN has been collecting data of VLBWIs in Korea and publishing annual reports and papers that provide an essential basis for QI and various clinical studies. Through these activities, the KNN helps facilitate improved outcomes of VLBWIs in Korea and provides necessary data for formulating future essential healthcare policies for newborns and premature infants.

Therefore, the KNN should be maintained and further developed to create population-based data-driven appropriate healthcare policies for high-risk infants. Furthermore, it can facilitate active neonatal multicenter research studies and QI for neonatal intensive care, ultimately leading to improved prognosis of high-risk newborns, including very preterm infants. Conse-

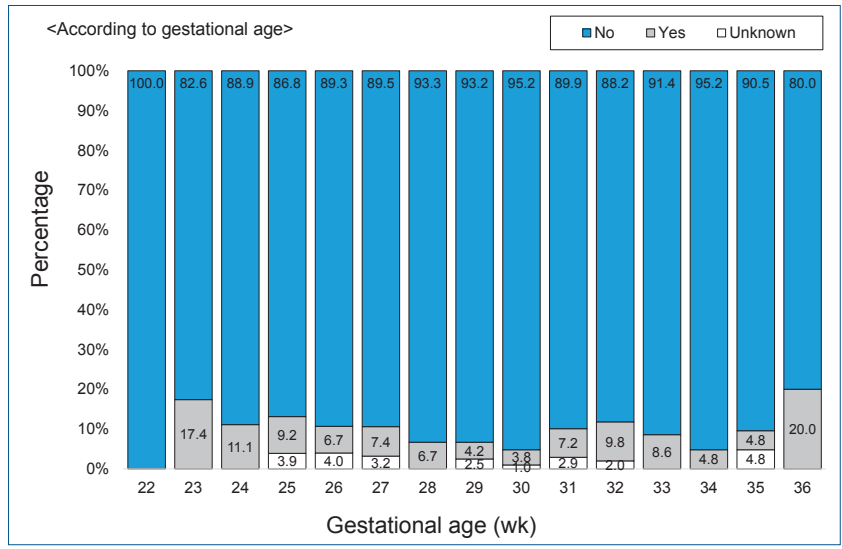

Fig. 2. Cerebral palsy cases by gestational age among very low birth weight infants born in 2013. Adapted from the Executive Committee of Korean Neonatal Network. 2013 Korean Neonatal Network Annual Report: Korean Centers for Disease Control and Prevention, 2014. ${ }^{19)}$

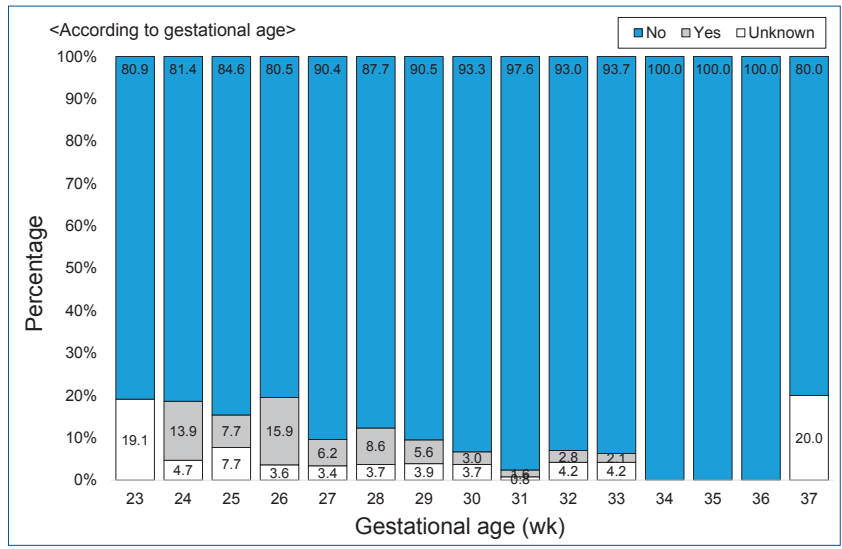

Fig. 3. Cerebral palsy cases by gestational age among very low birth weight infants born in 2014. Adapted from the Executive Committee of Korean Neonatal Network. 2014 Korean Neonatal Network Annual Report: Korean Centers for Disease Control and Prevention, 2015. ${ }^{20)}$ 
Table 4. Bayley scales of infant developmental outcomes: VLBWI born in 2013 vs. 2014

\begin{tabular}{|c|c|c|}
\hline Variable & 2013 & 2014 \\
\hline BSID 2nd ed. & 246 & 187 \\
\hline \multicolumn{3}{|l|}{$\mathrm{MDI}$} \\
\hline$<69$ & $55(22.4)$ & $45(24.1)$ \\
\hline $70-84$ & $64(26.0)$ & $46(24.6)$ \\
\hline $85-114$ & $109(44.3)$ & $84(44.9)$ \\
\hline$\geq 115$ & $18(7.3)$ & $12(6.4)$ \\
\hline \multicolumn{3}{|l|}{ PDI } \\
\hline$<69$ & $63(25.6)$ & $27(14.4)$ \\
\hline $70-84$ & $58(23.6)$ & $40(21.4)$ \\
\hline $85-114$ & $114(46.3)$ & 107 (57.2) \\
\hline$\geq 115$ & $11(4.5)$ & $13(7.0)$ \\
\hline BSID 3rd ed. & 77 & 121 \\
\hline \multicolumn{3}{|l|}{ Cognitive } \\
\hline$\leq 54$ & $0(0)$ & $0(0)$ \\
\hline $55-69$ & $6(7.8)$ & $5(4.1)$ \\
\hline $70-84$ & 9 (11.7) & $8(6.6)$ \\
\hline $85-114$ & $52(67.5)$ & $94(77.7)$ \\
\hline$\geq 115$ & $10(13.0)$ & $14(11.6)$ \\
\hline \multicolumn{3}{|l|}{ Language } \\
\hline$\leq 54$ & $2(2.6)$ & $2(1.7)$ \\
\hline 55-69 & $3(3.9)$ & $5(4.1)$ \\
\hline $70-84$ & $23(29.9)$ & $25(20.7)$ \\
\hline 85-114 & $44(57.1)$ & $73(60.3)$ \\
\hline$\geq 115$ & $5(6.5)$ & $16(13.2)$ \\
\hline \multicolumn{3}{|l|}{ Motor } \\
\hline$\leq 54$ & $4(5.2)$ & $2(1.7)$ \\
\hline $55-69$ & $6(7.8)$ & $2(1.7)$ \\
\hline $70-84$ & $8(10.4)$ & 15 (12.4) \\
\hline $85-114$ & $55(71.4)$ & $94(77.7)$ \\
\hline$\geq 115$ & $4(5.2)$ & $8(6.6)$ \\
\hline
\end{tabular}

Values are presented as number (\%).

VLBWI, very low birth weight infant; BSID, Bayley Scales of Infant Development; MDI, Mental Developmental Index; PDI, Psychomotor Develop mental Index

Modified from Youn et al. J Korean Med Sci 2018:33:e309. ${ }^{21)}$

quently, evidence-based neonatal medicine that can reduce healthcare costs may be developed in Korea.

\section{Conflicts of interest}

No potential conflict of interest relevant to this article was reported.

\section{Acknowledgments}

This research was supported by a fund (2016-ER6307-02\#) by Research of Korea Centers for Disease Control and Prevention.

\section{References}

1. Statistic Korea. Monthly, quarterly, and annual population trends (birth, death, marriage, divorce statistics) [Internet]. Daejeon (Korea): Statistic Korea; 2019 [cited 2019 Jun 7]. Available from: http://kosis.kr/statHtml/statHtml. do?orgId=101\&tblId=DT_1B8000G\&vw_cd=MT_ZTITLE\&list_d=
A2\&seqNo $=$ \&lang_mode $=$ ko\&language $=$ kor\&obj_var_id $=\& i t m \_i d=$ \& conn path $=$ MT ZTITLE.

2. Moon JY, Hahn W'H, Shim KS, Chang JY, Bae CW. Changes of maternal age distribution in live births and incidence of low birth weight infants in advanced maternal age group in Korea. Korean J Perinatol 2011;22:30-6.

3. Birth according to birth weight http://kosis.kr/statHtml/statHtml.do ?orgId=101\&tblId=DT_1B80A03\&vw_cd=MT_ZTITLE\&list_id $=\mathrm{A} 21 \&$ seqNo $=$ \&lang_mode $=$ ko\&language $=$ kor\&obj_var_id $=\&$ itm_id=\&conn_path=MT_ZTITLE Updated 2018-08-22, Accessed June 7, 2019

4. Chung JH, Phibbs CS, Boscardin WJ, Kominski GF, Ortega AN, Needleman J. The effect of neonatal intensive care level and hospital volume on mortality of very low birth weight infants. Med Care 2010;48: $635-44$.

5. Chang YS, Park HY, Park WS. The Korean Neonatal Network: an overview. J Korean Med Sci 2015;30(Suppl 1):S3-11.

6. The Executive Committee of Korean Neonatal Network. 2017 Korean Neonatal Network annual report. Cheongju (Korea): Korean Centers for Disease Control and Prevention, 2018.

7. Korean Neonatal Network. Status of registration in Korean Neonatal Network [Internet]. Seoul (Korea): Korean Neonatal Network; 2019 [cited 2019 Jun 7]. Available from: http://www.knn.or.kr/.

8. Liu L, Oza S, Hogan D, Perin J, Rudan I, Lawn JE, et al. Global, regional, and national causes of child mortality in 2000-13, with projections to inform post-2015 priorities: an updated systematic analysis. Lancet 2015; $385: 430-40$

9. Saigal S, Doyle LW. An overview of mortality and sequelae of preterm birth from infancy to adulthood. Lancet 2008;371:261-9.

10. Lee JH, Noh OK, Chang YS. Neonatal outcomes of very low birth weight infants in Korean Neonatal Network from 2013 to 2016. J Korean Med Sci 2019;34:e40.

11. Kinsella JP, Greenough A, Abman SH. Bronchopulmonary dysplasia. Lancet 2006;367:1421-31.

12. Majnemer A, Riley P, Shevell M, Birnbaum R, Greenstone H, Coates AL. Severe bronchopulmonary dysplasia increases risk for later neurological and motor sequelae in preterm survivors. Dev Med Child Neurol 2000; 42:53-60.

13. Van Marter LJ. Epidemiology of bronchopulmonary dysplasia. Semin Fetal Neonatal Med 2009;14:358-66.

14. Jo HS, Cho KH, Cho SI, Song ES, Kim BI. Recent changes in the incidence of bronchopulmonary dysplasia among very-low-birth-weight infants in Korea. J Korean Med Sci 2015;30(Suppl 1):S81-7.

15. Ancel PY, Goffinet F; EPIPAGE-2 Writing Group, Kuhn P, Langer B, Matis J, et al. Survival and morbidity of preterm children born at 22 through 34 weeks' gestation in France in 2011: results of the EPIPAGE-2 cohort study. JAMA Pediatr 2015;169:230-8.

16. Isayama T, Lee SK, Mori R, Kusuda S, Fujimura M, Ye XY, et al. Comparison of mortality and morbidity of very low birth weight infants between Canada and Japan. Pediatrics 2012;130:e957-65.

17. Stoll BJ, Hansen NI, Bell EF, Shankaran S, Laptook AR, Walsh MC, et al. Neonatal outcomes of extremely preterm infants from the NICHD Neonatal Research Network. Pediatrics 2010;126:443-56.

18. Stoll BJ, Hansen NI, Bell EF, Walsh MC, Carlo WA, Shankaran S, et al. Trends in care practices, morbidity, and mortality of extremely preterm neonates, 1993-2012. JAMA 2015;314:1039-51.

19. The Executive Committee of Korean Neonatal Network. 2013 Korean Neonatal Network annual report. Cheongju (Korea): Korean Centers for Disease Control and Prevention, 2014.

20. The Executive Committee of Korean Neonatal Network. 2014 Korean Neonatal Network annual report. Cheongju: Korean Centers for Disease Control and Prevention, 2015.

21. Youn Y, Lee SM, Hwang JH, Cho SJ, Kim EK, Kim EA. National registry data from Korean Neonatal Network: two-year outcomes of Korean very low birth weight infants born in 2013-2014. J Korean Med Sci 2018;33:e309.

22. Saigal S, den Ouden L, Wolke D, Hoult L, Paneth N, Streiner DL, et al. School-age outcomes in children who were extremely low birth weight 
from four international population-based cohorts. Pediatrics 2003;112: 943-50.

23. Anderson P, Doyle LW; Victorian Infant Collaborative Study Group. Neurobehavioral outcomes of school-age children born extremely low birth weight or very preterm in the 1990s. JAMA 2003;289:3264-72.

24. Breslau N, Chilcoat HD. Psychiatric sequelae of low birth weight at 11 years of age. Biol Psychiatry 2000;47:1005-11. 